Ankara Üniversitesi Türk İnkılâp Tarihi Enstitüsü Atatürk Yolu Dergisi

S 33-34, Mayıs-Kasım 2004, s. 15-22

\title{
Ankara'nın Merkez ve Başkent Olması
}

\author{
Doç. Dr. Oğuz AYTEPE*
}

\section{$\ddot{O Z E T}$}

19 Mayıs 1919'da millet egemenliğine dayanan tam bağımsız bir devlet kurmak amacıyla Samsun'a çıkan Mustafa Kemal Paşa Amasya Genelgesi'ni yayımladıktan sonra Erzurum Kongresini açmış ve orada Anadolu'yu yönetecek olan Heyet-i Temsiliye'yi kurmuştu. Erzurum'dan Sivas'a geçen Mustafa Kemal Sivas Kongresi'ni açmış ve onun da başkanı olmuştu. Sivas'ta çalışmalarını tamamlayan heyet merkez olarak Ankara'yı seçti ve oraya 27 Aralı 1919'da geldi. Ankara bu tarihten sonra ulusal hareketin yönlendirildiği merkez oldu. Mustafa Kemal Ankara'nın jeopolitik, stratejik ve coğrafi durumu, demiryolunun buradan geçmesi, savaş alanlarına yakın olması, Ankara halkının ulusal hareketi gönülden desteklemesi ve oluşan Kuva-yı Milliye ruhu, İstanbul'un siyasal ve toplumsal çevresine karşı duyulan güvensizlik nedenleriyle Ankara'yı başkent yaptı. İsmet İnönü ve ondört arkadaşının TBMM'ne verdikleri önerge ile Ankara 13 Ekim 1923 'de başkent oldu.

Anahtar Kelimeler: Ankara, Başkent, Mustafa Kemal Paşa, İsmet İnönü Heyet-i Temsiliye

\section{ABSTRACT}

Mustafa Kemal Pahsa went to Samsun on May 19, 1919 with the Amasya circular to published on 22 June, declared that the freedom of the nation shall be restored with the resolve and determination of the nation itself and called the meetings of the Sivas congress and acted as held. Than he returned to Ankara on December 1919, as it was choicen the centre for their work, Atatürk had choicen Ankara as the capital city its jeopilitic, strategic and geographical situation, railroads passings trough it, near to the war fields, the enthusiasm felt in Ankara

\footnotetext{
•Ankara Üniversitesi Türk İnkılâp Tarihi Enstitüsü Öğretim Üyesi.
} 
towards the national movement and their National Forces soul and the distrust felt against the politics and society of Istanbul

Key Words: Ankara, Capital, Mustafa Kemal Pasha, Ismet Inönü, Representative Committee

Birinci Dünya Savaşı'ndan yenik ayrılan Osmanlı Devleti şartları ağır bir ateşkes anlaşması imzalamıştı. Millet aralıksız süren savaşlar sonunda yorgun ve fakir bir durumdaydı. Ordunun elinden silahları alınmakta, galip devletler birer bahane ile ülkenin birçok bölgesini işgal etmekteydiler. Bu korkunç durum karşısında ülkenin birçok yerinde kurulan cemiyetler bölgesel önlemler almaya çalışıyorlardı. Mustafa Kemal Paşa bu cemiyetlerin aldığ 1 kararların hiçbirinde isabet görmüyordu. $O$ tam bağımsızlıkta direniyor, kurtuluş isteyenlerin parolası "ya istiklal ya ölüm" olmalıdır diyordu. Bu parolayı uygulayabilmek için, Türk yurduna saldıranlara silahla karşı konulacaktı. Uygulama safhalara ayrılacak, milletin duygu ve düşünceleri hazırlanarak adım adım hedefe ulaşılmaya çalışılacaktı.'

19. Mayıs 1919'da millet egemenliğine dayanan tam bağımsız bir devlet kurmak amacıyla 9. Ordu Müfettişi olarak Samsun'a çıkan Mustafa Kemal Paşa, bir hafta Samsun'da kaldıktan sonra 25 Mayıs'ta Havza'ya geçti. Tutum ve davranışları nedeniyle padişah tarafından İstanbul'a geri çağırıldı, ancak İstanbul'a dönmeyerek 12 Haziran'da Amasya'ya gitti. Buraya davet ettiği arkadaşları ve diğer yetkilerle anlaşarak Milli Mücadele' nin ihtilâl beyannamesi olan Amasya Genelgesi'ni yayımladı. Milletin bağımsızlığını yine milletin azim ve kararının kurtaracağı ve iki kongrenin açılacağı kamuoyuna duyuruldu.

Mustafa Kemal Paşa 26 Haziran'da Amasya'dan ayrıldı ve Tokat'tan geçerek 27 Haziran'da Sivas'a geldi. Aleyhinde propaganda yapan Elazı ğ Valisi Ali Galip'e hak ettiği dersi vererek 3 Temmuz 1919' da Erzurum'a geldi. Padişahın kendisini tekrar İstanbul'a çağırdığını ve görevine son verildiğini öğrenince 7/8 Temmuz 1919'da görevinden ve askerlik mesleğinden ayrıldı.

23 Temmuz 1919'da bir okul salonunda açılan Erzurum Kongresi'ne katıldı ve başkan seçildi. 14 gün süren kongrede; Milli Mücadele'nin hedef ve ilkeleri tespit edildi. Milli gücün teşkilatlanmasını sağlayacak kararlar alındı ve kamuoyuna duyuruldu. Bu kararları yürütmek üzere 9 kişilik bir "Heyet-i Temsiliye" seçildi. Başkanlığına da Mustafa Kemal Paşa seçildi. Heyet bir yandan Sivas Kongresi'nin hazırlıklarını yaparken bir yandan da Kuva-yi Milliye hareketine destek oldu.

\footnotetext{
${ }^{1}$ Mustafa Kemal Atatürk, Nutuk, C.I, Milli Eğitim Basımevi, İstanbul, 1973,s. 10 vd.
} 
Heyet-i Temsiliye, 29 Ağustos 1919'da Sivas Kongresine katılmak üzere Erzurum'dan ayrıldı. Erzincan boğazını Dersimli eşkiyaların tuttuğunun bildirilmesine rağmen Mustafa Kemal Paşa'nın aldırdı̆̆ önlemler sayesinde heyet 2 Eylül 1919'da Sivas'a geldi.

Sivas'ta beklenen delegeler henüz gelmediğinden kongre 4 Eylül'de açıldı. Kongrenin amacı, tüm ülkenin birlik ve beraberliğini sağlamaktı. Kongrenin ilk günü bazı delegelerin muhalefetine rağmen Mustafa Kemal Paşa başkanlığa seçildi. 11 Eylül'e dek süren Sivas Kongresi'nde Erzurum Kongresi tüzüğü ve alınan kararlar bazı değişiklikler yapılarak kabul edildi. ${ }^{2}$ Erzurum'da seçilen Heyet-i Temsiliye aynen korunmuş, Heyet-i Temsiliye'ye altı kişi daha seçilerek üye sayısı onaltıya çıkarılmış ve Anadolu ve Rumeli Müdafaa-i Hukuk Cemiyeti'nin Heyet-i Temsiliyesi haline gelmiştir. Milli Mücadele'nin beyni olan bu heyet T.B.M.M. açlıncaya kadar hükümet gibi çalışmıştır. ${ }^{3}$

Mustafa Kemal Paşa Sivas Kongresi sonunda İstanbul hükümeti ile temas kurmaya çalıştı. Yeni seçilen Sadrazam Ali Rıza Paşa ile anlaşarak Amasya'da 20-22 Ekim 1919'da toplantı yapıldı. Amasya Mülakatı sonunda alınan karara göre İstanbul Hükümeti, Sivas Kongresi'nde alınan kararları kabul edecekti. Ülkenin bölünmezliği, Meclis-i Mebusan'nın toplanması, Türklerin çoğunlukta olduğu yerlerin işgaline izin verilmemesi gibi hususlarda İstanbul Hükümeti elinden geleni yapacaktı. İstanbul Hükümetinin bir temsilcisinin Amasya'ya giderek Mustafa Kemal Paşa ile görüşmesi, Heyet-i Temsiliye ve milli teşkilatın artık hukuksal olarak Osmanlı Devletince tanındığı anlamına gelmekteydi.

Amasya protokolü gereği, Meclis-i Mebusan İstanbul dışında toplanacaktı. İstanbul Hükümetinin buna uymaması nedeniyle Mustafa Kemal Paşa Meclis-i Mebusan'ın toplanacağı yer konusunda kendi başına karar vererek bu kararı millet ve milletvekillerine uygulatmanın tehlikeli olacağını düşünmüş, vereceği kararın uygulanmasını sağlamak için ordunun görüşünü almak istemişti. Bu nedenle bazı kolordu komutanlarını Sivas'a toplantiya davet etti. 16-28 Kasım 1919'da yapılan Komutanlar Toplantısı'na Heyet-i Temsiliye üyeleri ve birçok kolordu komutanı katıldı. Meclis-i Mebusan'ın İstanbul'da toplanıp toplanmaması sorunu tartışıldı ve İstanbul'da toplanmasına karar verildi. ${ }^{4}$ Bu toplantıda Anadolu'da seçilen mebusların İstanbul'a gitmeden bir araya gelmeleri ve nerede toplanacakları da görüşüldü. Heyet-i Temsiliye'nin Eskişehir yakınlarına taşınması

${ }^{2}$ Tayyib Gökbilgin, Milli Mücadele Başlarkern, C. II, Ankara, Türk Tarih Kurumu Basımevi, 1965, s.9 vd.

${ }^{3}$ Bekir Sıtkı Baykal, Heyet-i Temsiliye Kararları, Ankara, Türk Tarih Kurumu Basımevi, 1975, s.IX -X.

${ }^{4}$ Bkz, Uluğ İ̆gemir (Haz.,) Heyet-i Temsiliye Tutanakları, Ankara, Türk Tarih Kurumu Basımevi,1975, 11-15. 
öngörüldü. ${ }^{5}$ Görüşmelerde Ali Fuat Paşa Eskişehir ve Seyitgazi üzerinde durmuş fakat sonunda buluşma yerinin Ankara olması kabul edilmişti. Bu kararın alınmasında, Ankara'da milli teşkilatın çok kuvvetli ve esas savaş alanı olan Batı Anadolu'ya yakın olması, İstanbul'a trenle bağlı olması önemli rol oynamıştı. ${ }^{6}$

Bu yolculuğun bir süre gizli tutulmasını isteyen Mustafa Kemal Paşa, güzergahın Kayseri ve Kırşehir üzerinden yapılacağını Fahrettin (Altay) Paşa' ya gönderdiği mektupta açıklamıştı. ${ }^{7}$ Mustafa Kemal Paşa karargah olarak Ankara'yı seçmişti. ${ }^{8}$ Bizim tespitlerimize göre, Ankara'nın merkez olması, Erzurum Kongresinin toplandığ 1 günlerde kararlaştırılmış ve bu durum 4 Ağustos 1919'da Mustafa Kemal Paşa tarafından, Ali Fuat Paşa' ya bildirilmiști. ${ }^{9}$ Ankara 20. Kolordu merkezi olmanın dişında, İstanbul'a demiryolu ile bağlıydı ve savaş alanlarına kolayca ulaşılabilirdi. Hükümet yanlısı Vali Muhittin Paşa işbaşından uzaklaştırılmıştı.

Mustafa Kemal Amasya Genelgesi'ni yayımladığı sırada, İzmir'in Yunanlılarca işgalini protesto eden Ankara halkı çağrıya derhal uyarak mitingler hazırlamıştı. Yurt savunmasına katılmak için özellikle 1919 Eylülü'nden sonra Müdafaa-i Hukuk-u Milliye merkezi kurulmuş, kazalarda da kurulan aynı addaki örgütler, düzenli bir eylem sağlanabilmesi için merkeze bağlanmışt. ${ }^{10}$

Kazım Karabekir Paşa Doğu'nun tek başına kalmasından yine karışıklığa düşmesinden korkuyor ve Heyet-i Temsiliye'nin değil Ankara'ya gitmek, Sivas'ın batısına bile geçmesini istemiyordu. ${ }^{11}$

${ }^{5}$ Uluğ İ̆demir, (Haz.), Heyet-i Temsiliye Tutanaklart, Ankara, Türk tarih Kurumu Basımevi, 1975, s.11.

${ }^{6}$ Mazhar Müfit Kansu, Erzurum'dan Ölümüne Kadar Atatürk'le Beraber, C. II, Ankara, Türk Tarih Kurumu Basımevi, 1968, s, 444 vd.

7 Taylan Sorgun, Imparatorluktan Cumhuriyete (Fahrettin Altay Paşa Anlattyor), İstanbul, Kamer Yayınları, 1998,s.199-200.

${ }^{8}$ Mustafa Kemal Paşa Ankara'nın merkez olarak seçilmesini şöyle açıklıyor; "Vaziyet-i umumiyeyi idare ve sevk mesuliyetini deruhte edenler, en mühim hedefe en yakın tehlike, mümkün olduğu kadar yakın bulunur. Yeter ki yakınlık vaziyet-i umumiyeti nazardan mehcur bırakacak derecede olmasın.Ankara bu şeraiti cam'i nokta idi. Her halde cephelerle iştigal edeceğiz diye Balıkesir'e Nazilli'ye veyahut Karahisar'a gitmiyorduk. Fakat cephelere ve İstanbul'a şimendiferlerle merbut ve vaziyet-i umumiyeyi idare nokta-i nazarından Sivas'tan asla farkı olmayan Ankara'ya gelecektik" Bkz., Nutuk, C.I., s.335.

${ }^{9}$ Mustafa Kemal Paşa,"Garbi Anadolu için en büyük merkez ve merciin Ankara olması muvafıktır " diyordu.Bkz, ATASE, (Askeri Tarih ve Stratejik Etüt Başkanlığı Arşivi), A.Ö.A., (Atatürk Özel Arşivi), Kl. 4-1, Ds. 335/ 2, Fh. 35 / 3.

${ }^{10}$ Seçil Akgün, “Ankara'nın Başkent Oluşu”, IX. Türk Tarih Kongresi, III. Cilt, T.T.K., Ankara, 1989,s.2070

${ }^{1}$ Mustafa Kemal Atatürk, Nutuk, C.I, İstanbul, 1973, s.406.; Kazım Karabekir, Istiklal Harbimiz, İstanbul, 1969, s.318. 
Seçimler yapılıp Meclisin açılmasının zamanı geldiğinde, Mustafa Kemal Paşa Heyet-i Temsiliye'nin Sivas'tan Ankara'ya hareketini 16 Aralık 1919'da ilgililere bildirmişti. ${ }^{12}$ Sivas'tan ayrılmak için yol hazırlıklarına başlanıldığında para ve benzin sorunları ile karşılaşılmıştı. Kurulun kasasında ancak birkaç lira bulunduğu görülmüştü.

Heyet-i Temsiliye ağırlığı 13 Aralık 1919 'da bir subay komutasında yola çıkarıld.$^{13}$ Heyet-i Temsiliye de 18 Aralık 1919 'da 3 araba ile sabah 9.00 'da yola çıtı. Heyet-i Temsiliye üyeleri ve kafile toplam 19 kişiden oluşuyordu. ${ }^{14}$

Kafile Kayseri, Kırşehir, Mucur ve Kaman yoluyla 27 Aralık 1919'da Ankara'ya ulaştı. Ankaralılar onları sevgi ile karşıladılar. Mustafa Kemal Paşa ve arkadaşları şehrin ileri gelenleriyle görüştü ve milli teşkilatın kuvvetlenmesi için gerekli tedbirleri ald ${ }_{1}{ }^{15}$ Mustafa Kemal Paşa ve Heyet-i Temsiliye üyeleri kendilerine tahsis edilen Kalaba'daki Ziraat Mektebi'ne yerleşti. Yayımlanan bir bildiri ile de Heyet-i Temsiliye'nin geçici merkezinin Ankara olduğu duyuruldu. ${ }^{16}$ Mazhar Müfit'e göre ; "Şimdilik Heyet-i Temsiliye merkezi Ankara'dır" diyorduk; halbuki biz çok evvel yani Sivas'ta Ankara'ya gitmeyi ve Ankara'nın daimi merkez olmasını kararlaştırmıştık. Fakat bu keyfiyeti, yani merkez-i hükümet olmasını mahrem tutuyorduk" diyordu. ${ }^{17}$ Ankara'nın merkez olarak seçilmesinin doğru bir karar olduğunu Kurtuluş Savaşı'nın gelişimi göstermiştir. Özellikle Sakarya Meydan Muharebeleri, yer seçiminin başarısını kanıtlamıştır. ${ }^{18}$

Mustafa Kemal Paşa ve arkadaşları olayların olumsuz yönde gelişmesine karşın Ankara'da özledikleri toplumsal dayanışmayı bulmuşlardı. Bu nedenle Ankara, Heyet-i Temsiliye' nin geçici merkezi olmaktan, Türkiye'nin başkenti durumuna yükselecektir.

Mustafa Kemal Paşa Milli Mücadele hareketini başlattı̆̆ında, komuta ettiği askeri birliklerin işgal bölgesinden daha içerilere çekilmesini istemiş. "daha o günlerden itibaren nüfuz ve iradesinin taalluk ettiği yerlerde milleti intihabata davet ve sırası geldiği zaman silaha sarılmak suretiyle hakkını ve yurdunu bizzat kurtarması için askeri teşkilatı vasıtasıyla emirler vermişti. Mustafa Kemal ordularının hazır vaziyetine rücu esnasında, Milli Harekete mihrak teşkil edecek olan Ankara ve civarında bu kıtaların naklolunmasını düşünmüştü"'19

\footnotetext{
${ }^{12}$ ATASE, TiH, (Türk Istiklal Harbi Arşivi), KI. 310, Ds. 44, Fh.48.

${ }^{13}$ ATASE, A.Ö.A., Kl. 15, Ds. 335 / 34, Fh. 4- 14.

${ }^{14}$ Heyetin ayrıntılı listesi için bkz., ATASE, A.Ö.A., Kl. 15, Ds. 335 / 34, Fh. 4 - 6 .

${ }^{15}$ Ömer Çelebi, Atatürk Kayseri'de, Ankara, 1973, s.52 v.d.

${ }^{16}$ Mustafa Kemal Atatürk, Nutuk, C.I., s.405.; Mazhar Müfit Kansu, a.g.e., C.II, s.500.

${ }^{17}$ Mazhar Müfit Kansu, a.g.e., C.II., s.500.

${ }^{18}$ Bilal Şimşir, Ankara Ankara, İstanbul, 1994, s.147-148.

${ }^{19}$ Ali Fuat Cebesoy, "Büyük Önderi karşılarken", Ulus, 29.12.1937.
} 
Ankara 27 Aralık 1919'dan başlayarak Türk ulusal hareketinin yönlendirildiği merkez olmuştu. Türkiye Büyük Millet Meclisi, yeni devlet orada kurulmuştu. Bu yönüyle yeni devletin gerçekte başkenti olmuştu.

Ankara'yı başkent yapan faktörlerin başında Ankara'nın jeopolitik, stratejik ve coğrafi konumu gelir. Ankara halkının Heyet-i Temsiliye'ye gösterdiği sıcak ilgi ve Milli Mücadele'ye verdiği destek. Ankara'da oluşan Kuva-yı Milliye ruhu. İstanbul'un siyasal ve toplumsal çevresine karşı duyulan güvensizlik de Ankara'nın başkent olmasında önemli etkenlerdendir. ${ }^{20}$

Ankara'nın başkent olma süreci TBMM'de oluşturulan bir komisyonun çalışmalarıyla başlamıştır. TBMM'nin yayımladığı 28 Kasım 1920 tarihli kararnamede ${ }^{21}$ başkent olacak yerin özellikleri belirtilmişti. Buna göre:

1.Başkent olarak düşünülen yerin seyrüsefer bir şehir ile bağlı olması.

2. Mülkün dört tarafına demiryollarıyla bağlılık imkanı bulunması.

3.Elektrik üretebilecek tabii veya suni şelalelere yakın olması.

4. Mümkün olduğu kadar kömür madeni civarında olması.

5. Ormanlık bir sahaya yakın bulunması

6. Genel ihtiyacı karşılayacak sulara sahip bulunması veya suların naklinin mümkün bulunmasi.

7. Bölgenin su ve havası.

8. Büyük bir şehir kurulabilecek araziye sahip olması.

9. Bina için inşa malzemesinin temininin mümkün olması.

10. Ve medeni bir şehir için bunlardan başka lüzumlu göreceği hususların lüzum ve vücuduna dikkat etmesine ve bu koşulları tamamı mevcut olmadığı halde koşulların ekseriyetine sahip bir yerin seçilmesi, koşulları ortaya konmuş ve 1921 kışında düşünülen başkente hükümetin nakledilmesine karar verilmişti. Meclis tarafından oluşturulan hükümet merkezi yerinin tayini için teşkil olunan komisyona İktisat Bakanlığından Orman ve Maadin Genel Müdürü Tahsin $\mathrm{Bey}^{22}$, Sihhiye Bakanlığından Doktor Nazmi Bey, Savunma Bakanlığından Erkanı Harbiye Kaymakamı Hulusi Bey memur edilmişlerdi. ${ }^{23}$ Genelkurmay Başkanlığı hükümet merkezi seçilecek yerin Kalecik-Sungurlu-Alaca-Akdağ Madeni- Şarkışla hattı ile bu

${ }^{20}$ Güven Dinçer, “Ankara'nın Başkent Oluşunun Anlamı” Atatürk Araştırma Merkezi Dergisi, S.37 (Mart 1997), s.229.

${ }^{21}$ Başbakanlık Cumhuriyet Arşivi (BCA), Fon, 030.18.1.1, Dosya, 21, Belge, 15.

${ }^{22}$ B.C.A., Fon, 030.18.1,1, Dosya, 21, Belge, 15, Ek: 1.

${ }^{23}$ B.C.A., Fon, 030.18.1,1, Dosya, 21, Belge, 15, Ek: 2. 
hattın güneyindeki Kızılırmak kavsi arasındaki sahada seçilmesinin milli hudut ve merkezi savunma noktasından uygun olacağını belirtmişti. ${ }^{24}$

Mustafa Kemal 1921'de yakınlarına Ankara'nın geleceğinden bahsetmiş, o yıl kendisini ziyaret eden Le Temps Gazetesi yazarı Mme. Gaulis'e "Siyasi bașkentimiz Anadolu'nun ortasında kalacaktır. Batının ve doğunun temsilcileri bizimle bu başkentte temas edeceklerdir.Bu başkentte her türlü diplomatik meseleler görüşülecektir.Bu başkentte memleketin iç ve dış politikası idare edilecektir. Bu başkentte milletin sinesinden doğan hükümet çalışacaktır. ${ }^{25}$ Demiş ve özel olarak, bu Anadolu kentinin Ankara olduğunu eklemişti. Ancak Mustafa Kemal bu düşüncesini açıklamayı ulusal hükümetin İstanbul üzerindeki iddialarını zayıflatacağı endişesiyle son derece sakıncalı görmüştü.

Mustafa Kemal başkent sorununu halletmek için Kurtuluş Savaşı'nın kazanılmasından sonra Lozan Antlaşması'nın imzalanmasını ve İstanbul'un İtilaf Devletlerinden kurtarılmasını beklemişti. Başkent konusunda kamuoyunun da hazırlanmasına önem vermişti. 1923 yılı Ocak ayında İzmit'te İstanbul gazeteleri başyazarlarıyla yaptığı görüşmede başkent sorununu da tartışma konusu yaptı. İstanbul'un işgal altında olmasına dikkat çekerek askeri açıdan sakıncalarını belirtti. Başkent olacak kentler arasında İzmir, Bursa, Eskişehir ve Ankara üzerinde durdu. Bu kentler arasında Ankara'nın başkent olabileceğini, iklim koşulları, Anadolu ile batının büyük merkezlerine demiryolu bağlantısı olduğunu, Kurtuluş Savaşı boyunca da fiili bir başkent görevi yaptığını ve bu görevi sürdürmesinin doğal ve haklı sayılabileceğini söyledi. Sırası geldiğinde bu hususun resmen açıklanacağı kanısında olduğunu belirtti. ${ }^{26}$

Lozan Antlaşması'nın 24 Temmuz 1923'te imzalanmasından sonra hükümet merkezi sorunu ele alındı. 9 Ekim 1923'te Malatya Mebusu İsmet Paşa ve 13 arkadaşı TBMM'ne bir kanun teklifi sunarak Ankara'nın başkent olmasını önermişler, önerge sahipleri gerekçelerinde ; Lozan tahliye protokolünden sonra işgal altında toprak kalmadığını, ülkenin bütünlüğü sağlandığını, Türkiye'nin idare merkezinin seçimi sırası geldiğini, Lozan'da kabul edilen hükümler (boğazlarla ilgili) nedeniyle ülkenin kuvvet kaynağını ve gelişmesini Anadolu'nun merkezinde, coğrafya ve stratejinin, iç ve diş güvenliğin gereklerini aramak zorunda olduklarını, ülkenin idare merkezi konusunda iç ve dış tereddütlere son vermek gerektiğini, bu merkezin Anadolu'da ve Ankara'da olması gerekli olduğunu belirtmişlerdi. ${ }^{27}$

Kanun önergesi 10 Ekim'de Anayasa komisyonuna sevk edildi. Tasarı TBMM Genel Kurulunda görüșüldü. Görüşmelerde Gümüşhane Mebusu

\footnotetext{
${ }^{24}$ BCA., Fon, 030.1.1, Dosya. 21, Belge, 15, Ek: 3.

${ }^{25}$ Enver Ziya Karal, Atatürk'ten Düşünceler, s.40 ; Seçil Akgün, a.g.m., s.2076.

${ }^{26}$ İsmail Arar, Atatürk'ün İzmit Basın Toplantısı, s.31-33.; Seçil Akgün, a.g.m., s.2078.

${ }^{27}$ İsmet İnönü, a.g.e., C. II. s.314 (Ek.5)
} 
Zeki Bey aleyhte görüş bildirdi. Ancak Celal Nuri ve Besim Atalay beyler hararetle Ankara'nın başkent olmasını savundular ve Genel Kurul'dan da büyük destek gördüler. ${ }^{28}$ Sonunda tasarı bir karşıt oyla TBMM'nin 27 numaralı kararı olarak 13 Ekim 1923 'de onaylandı ${ }^{29}$. Böylece Ankara "Devletin makkarı idaresi, Ankara şehridir" cümlesiyle fiilen olduğu gibi yasal olarak da başkent haline geldi.

${ }^{28}$ Güven Dinçer, a.g.m., s.228.

${ }^{29}$ Mahmut Goloğlu, Türkiye Cumhuriyeti 1923, Ankara, 1971, s. 302. 